\title{
Short Communication: Perception of synthetic biology application for biodiversity conservation among life science students in Institut Teknologi Bandung, Indonesia
}

\author{
RAHMAT AZHARI KEMAL \\ Department of Bio-Technology, School of Life Sciences, Indonesia International Institute for Life Sciences. Pulomas Barat Kav. 88, East Jakarta, \\ Indonesia, 13210. Tel./Fax.+6221-295-67888, email: rahmat.rakemal@gmail.com
}

Manuscript received: 6 January 2018. Revision accepted: 8 February 2018.

\begin{abstract}
Kemal RA. 2018. Short Communication: Perception of synthetic biology application for biodiversity conservation among life science students in Institut Teknologi Bandung, Indonesia. Nusantara Bioscience 10: 36-40. The emerging science of synthetic biology uses advanced engineering and biological science to re-design living organisms to carry out a specific function. Its application to biodiversity conservation seems promising yet barely addressed. Public perception of any emerging sciences and technologies should be studied. Therefore, this pilot study sought insight into the public perception of synthetic biology application to biodiversity conservation. As a pilot study, a web-based survey was designed for life science students in Institut Teknologi Bandung, Indonesia. Obtained responses were exported into Microsoft Excel and analyzed using SPSS 16.0. Results showed that respondents had a high agreement $(>75 \%)$ on biodiversity problems, but the attitude toward risk in tackling problems is more cautious yet still open to new conservation technology. The respondents' overall perception of synthetic biology application for biodiversity conservation was positive $(70 \%$ agreed/strongly agreed). The respondents perceived the application as risky but at the same time beneficial. There was a significant correlation between support for new technology development for biodiversity conservation with belief in promises that synthetic biology application's benefit $(0.549, \mathrm{p}<0.001)$. The respondents were still optimistic that the application would not decrease people's interest in biodiversity conservation. Results from this pilot study can serve as starting point for discussions and assessments of synthetic biology application in biodiversity conservation.
\end{abstract}

Keywords: Biodiversity, conservation, perception, synthetic biology

\section{INTRODUCTION}

Even though there is no universal definition about synthetic biology (Hagen et al. 2015), the emerging science can be defined as the use of advanced engineering and biological science to construct or re-design living organisms to carry out specific function (Pauwels 2013). Modularisation, rationalization, and modelling of biomolecular networks allow programmable and controllable of cellular behavior and phenotype (Khalil and Collins 2010; Ruder et al. 2011). Synthetic biology can address many problems such as famine, disease, and energy shortage. Its practical applications in biosensing, therapeutics, and productions of chemicals (biofuels, pharmaceuticals, and novel biomaterials) have been reviewed (Khalil and Collins 2010).

One area less explored for synthetic biology application is biodiversity conservation. There are several potential applications (Redford et al. 2014) that may have a direct or indirect impact on biodiversity conservation. Problems such as diseases and invasive species may be solved by synthetic biology. The more imaginative idea of the resurrection of extinct species (de-extinction) has fascinated public mind. Applications to restore degraded or polluted area and to provide alternatives to detrimental patterns of human consumption and production may have an indirect impact on biodiversity. But synthetic biology does not only provide solutions but also become problems as well (Redford et al. 2013). Problems addressed are not only technical but also societal and ethical (Wolfe 2015). If synthetic biology is to be applied to biodiversity conservation, its public perception and acceptance should be studied because public perception and acceptance form one aspect in developing science and technology (Torgersen 2009; Pardo Avellaneda and Hagen 2016). This pilot study focused on life science-related university students. The survey conducted in 8 European countries showed that $20.6 \%$ of respondents would not be able to explain "biodiversity" even though they have heard about it, while bigger portion $(28.6 \%)$ never heard about the term (Bednar-Friedl et al. 2009). Therefore the students were expected to have background knowledge of the terms used in this survey, especially the term "biodiversity". The result from this study is expected to give a brief outlook of Indonesian public perception.

\section{MATERIALS AND METHODS}

\section{Questionnaire design}

A web-based survey was designed to solicit responses on perception about synthetic biology in general and collaboration between synthetic biology and biodiversity conservation. Questions are grouped into three categories. 
The first category is for demographic data collection consisting of a name of major and university, and level of study s(undergraduate and graduate). The second category assessed respondent's views on biodiversity theme such as problem acknowledgment, attitude towards risk, and support for new technology development. Before answering the third category, brief explanations about synthetic biology's definition and application were provided based on (Pauwels 2013). The third category assessed respondent's perception of synthetic biology application such as approval of applications (overall and specific) and perception of effects (risks and benefits). Second and third categories were measured on a scale from $1=$ "strongly disagree" to 5 = "strongly agree".

\section{Data collection and analysis}

Respondents selected were undergraduate and graduate students majoring life sciences in Institut Teknologi Bandung (ITB). The survey was available in the form of Google Form, and the responses were collected within 2 weeks from June 6-19, 2016. Questionnaire data were exported into Microsoft Excel for analysis with only valid responses were evaluated. Statistical analysis was calculated using SPSS 22.0. Correlation evaluation was calculated using Spearman's rho.

\section{RESULTS AND DISCUSSION}

During the active period of the survey, a total of 103 responses were received. Seven responses were excluded because they did not originate from target major, 3 responses were excluded because of not citing their major, 1 response was excluded because of not citing the university, and 42 responses were excluded because they did not originate from ITB. The remaining 50 valid responses were used for analysis. Among valid responses, responses have equal distribution among the level of study, 25 responses $(50 \%)$ for both undergraduate and graduate students.

\section{Views on biodiversity}

Majority of respondents agreed about current biodiversity problems, and almost all respondents (92\%) agreed that biodiversity conservation is needed (Table 1). However, significantly more people expressed neutrality when addressing problems compared to the need for conservation $(\mathrm{p}<0.05)$.

In tackling biodiversity problems, the only small majority agreed that risks are worth taking (54\%). Even though most people (70\%) agreed that risks should be minimized, respondents still agreed that inaction about extinction might be riskier $(60 \%)$. Majority respondents $(72 \%)$ still supported the idea of the development of new technologies for biodiversity conservation. Table 2 shows correlation between views on biodiversity (BD). Acknowledgement of endangered status of many species correlates strongly with the need for conservation $(\rho=0.702, p<0.001)$. A significant positive correlation was observed between the cautious attitude of minimizing risk in conservation actions with concern for biodiversity problems, especially the human activity's negative impact on biodiversity $(\rho=0.406, p<0.01)$. Respondent's view that risks are worth taking has significant positive correlation with view of inaction's risks $(\rho=0.628, p<0.001)$. The need for biodiversity conservation has the strong positive correlation with the support of new technology development for conservation $(\rho=0.599, p<0.001)$.

\section{Perception of synthetic biology application}

Perception of synthetic biology application to a different field (Figure 1.A) was significantly different $(\mathrm{p}<0.001)$. More respondents agree with health application $(84.8 \%)$ than with biodiversity conservation (69.5\%). It is also reflected in public perception of examples of each application (Figure 1.B). The significant difference $(p<0.001)$ was also reflected in individual specific applications. Most respondents agree for application to produce new drug/medicine and new diagnostic $(83.7 \%$ and $88 \%$, respectively). When addressing more realistic biodiversity problems, such as preventing diseases attacking wildlife and controlling invasive species, the majority of respondents agreed $(65.2 \%$ and $63.1 \%$, respectively) with relatively small minority disagreed (9.4\% and $9.8 \%$, respectively). When the more futuristic problem, such as resurrecting extinct animals, was addressed, only $51.1 \%$ agreed with $19.6 \%$ of the respondents disagreed. This was the lowest support and highest opposition among five potential applications addressed.

Table 3 shows respondent's perception of effects of synthetic biology application for biodiversity conservation. There is no significant difference in respondent's perception of positive and negative framing statements. More than half of the respondents agreed that organisms created by synthetic biology could evolve into invasive species or unintentionally escape into the environment (66\% for both). Table 4 shows correlation between perception of synthetic biology application (SB) views on biodiversity (BD) There seems to be a positive correlation between the awareness of human activity's negative impact on biodiversity (BD2) with the concern of synthetic organism's ability to evolve into invasive species $(\rho=0.299$, $p<0.05)$ and the risk of unintentional escape $(\rho=0.403$, $\mathrm{p}<0.01$ ). However, a small majority of respondents are still optimistic that the application will solve environmental problems caused by human activities (62\%), increase wildlife survival (46\%). However, only $38 \%$ of respondents agreed that synthetic biology could provide more habitats for wildlife, while the majority of the respondents $(52 \%)$ expressed neutrality. Support for new technology development for biodiversity conservation (BD7) correlated significantly with belief in promises that synthetic biology application can solve environmental problems caused by human activities $(\rho=0.549, p<0.001)$. The statement that synthetic biology application will decrease people's interest in biodiversity conservation was only supported by $28 \%$ of respondents, rejected by $24 \%$, the majority (48\%) did not express opinion. 
Table 1. Respondent's views on biodiversity

\begin{tabular}{|c|c|c|c|}
\hline \multirow[b]{2}{*}{ Statements } & \multicolumn{3}{|c|}{ Views (\%) } \\
\hline & $\begin{array}{c}\text { Strongly } \\
\text { agree/agree }\end{array}$ & Neutral & $\begin{array}{c}\text { Disagree/ } \\
\text { strongly } \\
\text { disagree }\end{array}$ \\
\hline \multicolumn{4}{|l|}{ Problem acknowledgement } \\
\hline [BD1] Many species are endangered & 76 & 22 & 2 \\
\hline [BD2] Human activities have negative impacts on biodiversity & 84 & 14 & 2 \\
\hline [BD3] Biodiversity conservation is needed & 94 & 6 & 2 \\
\hline \multicolumn{4}{|l|}{ Attitude towards risk } \\
\hline [BD4] Risks in taking actions regarding conservation should be minimized & 70 & 26 & 4 \\
\hline [BD5] Inaction about extinction may be riskier than actions without full knowledge of consequences & 60 & 26 & 14 \\
\hline [BD6] Risks are worth taking for conservation of biodiversity & 54 & 32 & 14 \\
\hline \multicolumn{4}{|l|}{ Support for new technology development } \\
\hline [BD7] New technologies should be developed for biodiversity conservation & 72 & 24 & 4 \\
\hline
\end{tabular}

Table 2. Correlation between views on biodiversity

\begin{tabular}{|c|c|c|c|c|c|c|c|}
\hline Statement & BD1 & BD2 & BD3 & BD4 & BD5 & BD6 & BD7 \\
\hline [BD1] Many species are endangered & & $0.408^{* *}$ & $0.702^{* * *}$ & $0.340^{*}$ & 0.276 & 0.109 & $0.387^{* *}$ \\
\hline [BD2] Human activities have negative impacts on biodiversity & $0.408^{* *}$ & & $0.444^{* *}$ & $0.406^{*}$ & $0.536^{* * *}$ & $0.329^{*}$ & $0.411^{* *}$ \\
\hline [BD3] Biodiversity conservation is needed & $0.702^{* * *}$ & $0.444^{* *}$ & & $0.326^{*}$ & $0.340^{*}$ & 0.239 & $0.599^{* * *}$ \\
\hline $\begin{array}{l}\text { [BD4] Risks in taking actions regarding conservation should be } \\
\text { minimized }\end{array}$ & $0.340^{*}$ & $0.406^{* *}$ & $0.326^{*}$ & & $0.432^{* *}$ & $0.382^{* *}$ & $0.520^{* * *}$ \\
\hline $\begin{array}{l}\text { [BD5] Inaction about extinction may be riskier than actions without } \\
\text { full knowledge of consequences }\end{array}$ & 0.276 & $0.536^{* * *}$ & $0.340^{*}$ & $0.432^{* *}$ & & $0.628^{* * *}$ & $0.524^{* * *}$ \\
\hline [BD6] Risks are worth taking for conservation of biodiversity & 0.109 & $0.329^{*}$ & 0.239 & $0.382^{* *}$ & $0.628^{* * *}$ & & $0.462^{* *}$ \\
\hline $\begin{array}{l}\text { [BD7] New technologies should be developed for biodiversity } \\
\text { conservation }\end{array}$ & $0.387^{* *}$ & $0.411^{* *}$ & $0.599^{* * *}$ & $0.520^{* * *}$ & $0.524^{* * *}$ & $0.462^{* *}$ & \\
\hline
\end{tabular}
$\frac{\text { conservation }}{{ }^{*} \mathrm{p}<0.05 ;{ }^{* *} \mathrm{p}<0.01 ;{ }^{* * *} \mathrm{p}<0.001}$

\section{Discussion}

While the need for biodiversity conservation was acknowledged, there seems to be more neutrality when addressing biodiversity problem, such as the high number of endangered species. A study by Novacek (2008) also showed that while there is a high public concern about biodiversity problem, basic messages about biodiversity critical situation has not been effectively delivered to the public. Some strategies have been recommended, such as focusing on paying attention, recrafting, and improving deliverance to impact the diverse public (Novacek 2008). In Indonesia, media exposure about Sumatran tiger decreased its hunting (Hendry 2016), therefore showing media's valuable position as audience and partner in delivering the message and eliciting public engagement.

Respondents had a cautious attitude toward risk regarding biodiversity. The cautious attitude correlated with acknowledgement of human activity's negative impact on biodiversity. Such correlation between concern of environmental problems and reservation of science and technology, in general, has been observed in American public (Xiao 2013). Attitudes towards biodiversity management are influenced by representations of biodiversity and nature (Buijs et al. 2008). Although people agree on the need of protecting nature, some have an absolute ecocentric view, favoring hands-off management where nature to be left alone without interference (Buijs et al. 2008; Sharp et al. 2011). However, the cautious attitude seems to not be followed by technology skepticism. Among respondents, the need for conservation has a strong positive correlation with the support of new technology development. A similar result was also found in the more general term that concern for global environmental problems increases support for science and technology (Xiao 2013). This optimism can be a good starting point for exploration of synthetic biology application to biodiversity conservation. 

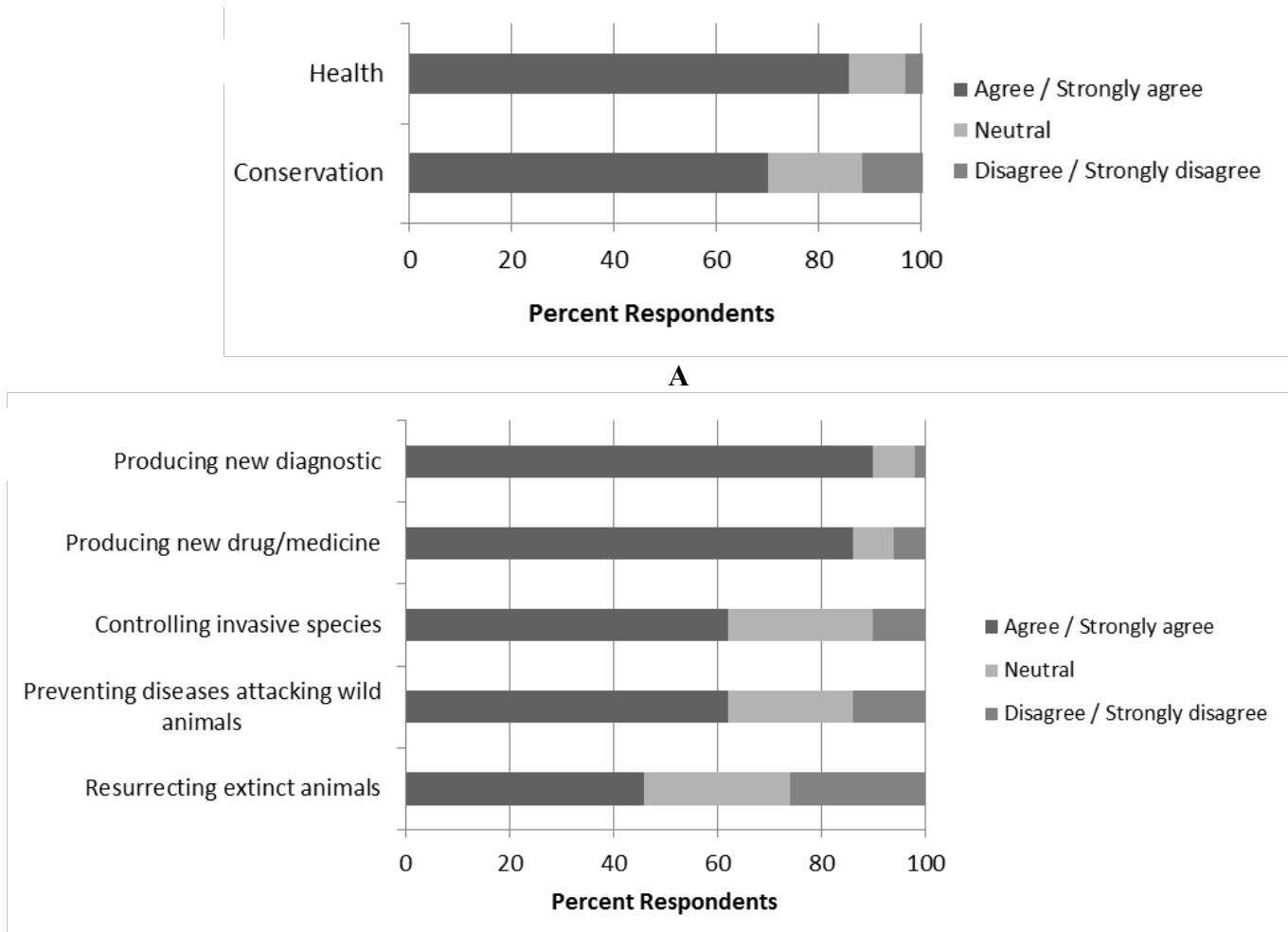

B

Figure 1. Respondent's perception on (A) overall and (B) specific application of synthetic biology to different fields showed higher support for health application compared to biodiversity conservation.

Table 3. Respondent's perception of effects of synthetic biology application for biodiversity conservation

\begin{tabular}{|c|c|c|c|}
\hline \multirow[b]{2}{*}{ Statements } & \multicolumn{3}{|c|}{ Views (\%) } \\
\hline & $\begin{array}{c}\text { Strongly } \\
\text { agree/agree }\end{array}$ & Neutral & $\begin{array}{c}\text { Disagree/strongly } \\
\text { disagree }\end{array}$ \\
\hline \multicolumn{4}{|l|}{ Positive effects } \\
\hline [SB1] Synthetic biology can solve environmental problems caused by human activities & 62 & 34 & 4 \\
\hline [SB2] Synthetic biology can increase the survival of wildlife & 46 & 42 & 12 \\
\hline [SB3] Synthetic biology can provide more habitat for wildlife & 38 & 52 & 10 \\
\hline \multicolumn{4}{|l|}{ Negative effects } \\
\hline [SB4] Organism(s) created by synthetic biology can evolve into invasive species & 66 & 22 & 12 \\
\hline [SB5] Organism(s) created by synthetic biology can unintentionally escape into environment & 66 & 26 & 8 \\
\hline [SB6] Synthetic biology can decrease people's interest in biodiversity conservation & 28 & 48 & 24 \\
\hline
\end{tabular}

Table 4. Correlation between perception of effects of synthetic biology application and views on biodiversity

\begin{tabular}{|c|c|c|c|c|c|c|c|}
\hline Statement & BD1 & BD2 & BD3 & BD4 & BD5 & BD6 & BD7 \\
\hline $\begin{array}{l}\text { [SB1] Synthetic biology can solve environmental problems caused by } \\
\text { human activities }\end{array}$ & $0.358^{*}$ & $0.393^{* *}$ & $0.406^{*}$ & $0.304^{*}$ & $0.280^{*}$ & 0.102 & $0.549^{* * *}$ \\
\hline [SB2] Synthetic biology can increase the survival of wildlife & 0.082 & 0.209 & -0.004 & 0.143 & 0.174 & 0.106 & 0.215 \\
\hline [SB3] Synthetic biology can provide more habitat for wildlife & 0.212 & 0.116 & 0.109 & $0.413^{* *}$ & 0.266 & 0.219 & 0.261 \\
\hline $\begin{array}{l}\text { [SB4] Organism(s) created by synthetic biology can evolve into invasive } \\
\text { species }\end{array}$ & 0.069 & $0.299^{*}$ & 0.048 & $0.309^{*}$ & 0.206 & 0.145 & 0.085 \\
\hline $\begin{array}{l}\text { [SB5] Organism(s) created by synthetic biology can unintentionally escape } \\
\text { into environment }\end{array}$ & 0.099 & $0.403^{* *}$ & 0.202 & 0.035 & $0.354^{*}$ & 0.162 & 0.044 \\
\hline $\begin{array}{l}\text { [SB6] Synthetic biology can decrease people's interest in biodiversity } \\
\text { conservation }\end{array}$ & 0.017 & 0.271 & -0.008 & 0.258 & $0.301^{*}$ & 0.103 & 0.046 \\
\hline
\end{tabular}


Different public perception of different specific applications was also observed in different surveys with effects on environment concerned the respondents (Pauwels 2009, 2013). This perception may arise due to some level of controllability in confined laboratories compared to uncontrolled evolution and mutation of the released organisms in open environments (Hagen et al. 2015). Regarding perceived impacts, respondents perceived effects of synthetic biology application to biodiversity conservation to be risky but yet beneficial. Observed reservation can be influenced by the environmental concern which stems from other noticeable problems related to science and technology, such as global warming (Xiao 2013). However, respondents are still optimistic about the application. From a focus-group discussion Austria, the student group also thought that synthetic biology provides opportunities but needs to minimize potential risks by control and legal efforts (Kronberger et al. 2012).

One concern about synthetic biology application to biodiversity conservation is the reduction of society and policymakers willingness to conserve biodiversity (Redford et al. 2013). The premise that extinction may not be forever (Kumar 2012) and other premises provided by synthetic biology application may reduce support for conserving endangered species, preserving protected areas, and addressing underlying causes for biodiversity loss (Redford et al. 2013). The concern was reflected in the survey result.

Perceptions derived from this survey can give an overview of potential discussions when synthetic biology is applied to biodiversity conservation. We have seen digital technology applied to conservation with its possibilities and problems have been discussed (Arts et al. 2015). The growth of digital technology application to nature conservation faces problems such as hypes, techno-fix thinking, unverified promises, and good-news narrative (Arts et al. 2015), similar to problems faced by synthetic biology in general. When addressing risks and risk perceptions in general, lessons can be learned from nanotechnology. Differences on perception (more or fewer risks) and kinds of risks more concerned (societal, health, and environment) between experts and lay people may be due to the lack of understanding of fundamental concepts in lay people (Siegrist 2010). Therefore, education plays an important role in forming perceptions.

This pilot study has captured the perception of life science students from ITB on biodiversity and the potential application of synthetic biology for biodiversity conservation. The study does not expect to represent overall Indonesian public perception due to the relatively small and specific sample. Some bias might also occur due to the initial familiarity of ITB students on synthetic biology. Synthetic biology has been integrated into ITB's School of Life Sciences in the form of compulsory course for Biology undergraduate programme as well as participation in iGEM (Suhandono 2017).

The university students targeted as respondents are expected to have high education level and high sensitivity to new information (Zhang et al. 2013), but even a minority of the respondents doubts biodiversity problems. Thus if the study's result is projected to larger populations, there will be some proportion of Indonesia's general population having the same perception. Larger scale quantitative surveys, as well as qualitative surveys such as focus-group discussion, need to be conducted to get a more comprehensive understanding of this matter. For future surveys, discussions, and assessments, this study provides insights on views and perceptions regarding biodiversity and synthetic biology among Indonesian lay people.

\section{REFERENCES}

Arts K, van der Wal R, Adams WM. 2015. Digital technology and the conservation of nature. Ambio 44 (Suppl. 4): S661-S673.

Bednar-Friedl B, Buijs A, Dobrovodská M, et al. 2009. A long-term biodiversity, ecosystem, and awareness research network-results from a (pilot) survey in 8 European countries. Project no. GOCE-CT-2003505298 ALTER-Net. Macaulay Land Use Institute, Alterra, UBA.

Buijs AE, Fischer A, Rink D, Young JC. 2008. Looking beyond superficial knowledge gaps: understanding public representations of biodiversity. Intl J Biodivers Sci Manag 4: 65-80.

Hagen K, Engelhard M, Toepfer G. 2015. Ambivalences of Creating Life: Societal and Philosophical Dimensions of Synthetic Biology. Springer International Publishing, Berlin.

Hendry D. 2016. Empat tahun penjara, hadiah untuk pembunuh harimau Sumatera. http:/www.mongabay.co.id/2016/06/23/empat-tahunpenjara-hadiah-untuk-pemburu-harimau-sumatera/

Khalil AS, Collins JJ. 2010. Synthetic biology: applications come of age. Nat Rev Genet 11:367-379.

Kronberger N, Holtz P, Wagner W. 2012. Consequences of media information uptake and deliberation: focus groups' symbolic coping with synthetic biology. Public Underst Sci 21 (2): 174-187.

Kumar S. 2012. Extinction need not be forever. Nature 492: 9.

Novacek MJ. 2008. Engaging the public in biodiversity issues. Proc Natl Acad Sci USA 105 (S1): 11571-11578.

Pardo Avellaneda R, Hagen K. 2016. Synthetic Biology: Public Perceptions of an Emergent Field. In: Engelhard M (ed) Synthetic Biology Analysed. Springer International Publishing, Berlin.

Pauwels E. 2013. Public understanding of synthetic biology. BioScience 63 (2): 79-89.

Pauwels E. 2009. Review of quantitative and qualitative studies on U.S. public perceptions of synthetic biology. Syst Synth Biol 3 (1): 37-46.

Redford KH, Adams WM, Carlson R, Mace GM, Ceccarelli B. 2014. Synthetic biology and the conservation of biodiversity. Oryx 48 (3): 330-336.

Redford KH, Adams W, Mace GM. 2013. Synthetic biology and conservation of nature: wicked problems and wicked solutions. PLoS Biol 11 (4): e1001530. DOI: 10.1371/journal.pbio.1001530.

Ruder WC, Lu T, Collins JJ. 2011. Synthetic biology moving into the clinic. Science 333: 1248-1252.

Sharp RL, Larson LR, Green GT. 2011. Factors influencing public preferences for invasive alien species management. Biol Conserv 144: 2097-2104.

Siegrist M. 2010. Predicting the future: Review of public perception studies of nanotechnology. Hum Ecol Risk Assess 16: 837-846.

Suhandono S. 2017. Synthetic biology: Emerging bioengineering in Indonesia. AIP Conf Proc 18844: 030001-1-030001-8. DOI: $10.1063 / 1.4983428$

Thamamongood T, Lim NZL, Ho TYH, Ayukawa S, Kiga D, Chow KL. 2013. Cultivation of synthetic biology with the iGEM competition. J Adv Comput Intell Intell Inform 17 (2): 161-166.

Torgersen H. 2009. Synthetic biology in society: learning from past experience? Syst Synth Biol 3 (1): 9-17.

Wolfe AK. 2015. Societal aspects of synthetic biology: organisms and applications matter! J Responsib Innov 2 (1): 121-123.

Xiao C. 2013. Public attitudes toward science and technology and concern for the environment: testing a model of indirect feedback effects. Environ Behav 45 (1): 113-137.

Zhang L, He G, Mol APJ, Lu Y. 2013. Public perceptions of environmental risk in China. J Risk Res 16 (2): 195-209. 